\title{
An Exploratory Factor Analysis of Quality of Work Life of Pilots
}

\author{
Iratrachar Amornpipat \\ Kasem Bundit University, Bangkok, Thailand
}

\begin{abstract}
This study aims to explore dimensions of quality of work life (QWL) of pilots by using an exploratory factor analysis (EFA). The sample was 400 pilots who are currently working for an airline based in Thailand. The items using in this study were generated using input from three sources. First, using input from commercial pilots who had a minimum of total 5,000 flying hour and currently working for either premium or low cost airlines in Thailand. Second, translated quality of work life items from a published research on Quality of Work Life of Personnel at Dhurakij Pundit University by Chatthai (2016). After the content analysis, the left items for the EFA analysis were 30 items. The Kaiser-Meyer-Olkin (KMO) demonstrated at 0.93 . The exploratory factor analysis was to examine the loading patterns of QWL items. A principal component and orthogonal rotation (Verimax method) were chosen. It showed there were five structural factor patterns. The five factors were labored as "Human Resource Management"; "Social Relation"; "Safe Working Environment"; "Work-Life Balance"; and "Fairness and Respect". Discussion and future research are also discussed.
\end{abstract}

Keywords: quality of work life, pilot, aviation, Thailand

\section{Introduction}

It can be seen that pilots play a crucial role in the aviation industry. They are the ones who are responsible for lives of people who are in the aircraft. Pilots' effectiveness may have an impact on safe operations. It is mainly because they have to face various stressful situations such as large amount of information and complicated technology of aircraft operation. This also includes their technical skills, psychological and physical wellbeing, and welfare issue. These factors are found to have an effect on pilots' performance (Civil Aviation Safety Authority, 2017).

Quality of work life (QWL) can be used as a strategy for the airline industry to promote an increase of QWL among pilots; this could subsequently attract and retain skilled employees. This study aims to explore the dimensions of QWL of pilots. This paper begins with literature review related to QWL and working context of pilots. It is then followed by methods of exploratory factor analysis, discussion, and conclusion.

\section{Literature Review}

\section{Quality of Work Life (QWL)}

The term QWL has been traced in the early 1960s, and gained momentum after being endorsed by the American Society of Training and Development (ASTD). ASTD referred QWL as the means that the management of a 
company ensures all its employees participate in shaping its environment. Robbins (1989) defined QWL as "a process by which an organization responds to employee needs by developing mechanisms to allow them to share fully in making the decisions that design their lives at work" (p. 207). The definitions of QWL are aligned with other scholars such as Daubermann and Pamplona (2012); Heidari, Enayati, and Hedayati (2010), that considered QWL as a process that organisation and stakeholders learn to work better together to improve both quality of their employees and organisational effectiveness. Lau (2000) identified QWL as workplace strategies, operations, and environment that promote and maintain employee satisfaction aimed at providing the favourable conditions and environments of a workplace that support and promote employees' satisfaction.

There is substantial amount of studies on QWL; this leads to various definitions describing the meaning of QWL (Krueger, Brazil, Lohfeld, Edward, Lewis, \& Tjam, 2002). The concept of QWL has not yet been formalised, however, there is some certain level of agreement among scholars that QWL is a multi-dynamic concept which covers several dimensions (Adhikari \& Gautam, 2010). Walton (1975) proposed that QWL comprised of eight dimensions, which are adequate and fair compensation; safe and healthy environment; growth and security; development of human capabilities; the total life space; social integration; constitutionalism; and social relevance. Mirsepasi (2005) suggested that QWL consisted of two dimensions including (1) objective dimension - the actual experiences of work place including reward systems, work environment, task variety, and safety and health issues; (2) subjective dimension—employees' attitudes of the QWL at their workplace. This may be their perceptions towards organisational fairness, and relationships with supervisors and management.

Later, the concept of QWL could cover an opportunity for constant learning and development of new skills, and participative decision making (Rossi, Perrewee, \& Sauter, 2006). Further, the key element of the QWL on job security has been emphasized by several scholars (Jegak, Asiah, Noor, Bahaman, Jamilah, \& Thomas, 2010). It could be because job security has a direct impact on work motivation and performance among employees. Burchell and Robin (2011) also found that employees who feel proud of their job, have a sense of belonging to the company, are treated fairly, have the possibility to involve in decision making process, have healthy relationship between individuals, are satisfied with total working environment, and have work-life balance tend to increase their motivation and job satisfaction. This can be implied that their QWL may be considerably improved (Burchell \& Robin, 2011; Cunningham \& Eberle, 1990; Hunker, 2014; Nekouei, Othman, Masud, \& Ahmad, 2014).

\section{Working Context of Pilots}

Pilots experience the risk of not spending adequate time with their families. Pilots who work for commercial airlines travel from the main operating airport to various destinations. These destinations are the different countries around the world. Commercial pilots usually have many complicated tasks to perform; these are shared between the main pilot and the co-pilot. The workload varies during the flight but mostly becomes complicated during communication breakdown and adverse weather conditions (Gentili et al., 2014). During high workload, pilots are vulnerable to errors, which sometimes psychologically break them down (Dorneich et al., 2011). A recent research by Wiegmann and Shappell (2017) showed a significant number of pilot errors occur due to the complexity of the cockpit, which contributed to airline accidents.

Due to their demanding work, lack of efficient work-life schemes may lead to mental health problems in pilots. This risk involves pilots experiencing stress, depression and even having suicidal thoughts. According to Otto and Webber (2013), pilots risk suffering from clinical depression, which is common in people working in high stress occupations. 


\section{Methods and Results}

This section explains the processes and analysis of QWL of pilots. The process started by generating items based on literature reviews and experts in the field.

\section{Population and Sample}

Population was Thai commercial pilots who are currently working for Bangkok Airways. The sample of 400 Thai Pilots was selected by using the purposive sampling, only captain and first officer. The quota sampling was also applied. As a result, the sample included $50 \%$ of premium airlines, and the other half for the low cost airlines. The instrument for data collection was online questionnaires.

The sample included 400 pilots comprising of 218 Captains (54.5\%) and 182 First Officers (45.5\%). The majority of the participants (141 pilots-35.3\%) had total flight hours between 1,001-5,000 hours. It was followed by the 138 pilots $(34.5 \%)$ with total flight hours that was above 10,001 hours. The marital status of being married included 220 pilots $(55.0 \%)$ while the single status was 180 pilots $(45.0 \%)$.

\section{Item Generation}

The items using in this study were generated using input from three sources. First, using input from commercial pilots who had a minimum of total 5,000 flying hour and currently working for either premium or low cost airlines in Thailand. Second, translated quality of work life items from a published research on Quality of Work Life of Personnel at Dhurakij Pundit University by Chatthai (2016). Last, items generated by the authors based on literature review. Having produced a preliminary set of 43 items, the rating employed was a Likert scale ranging from: $5=$ Strongly Agree; 4 = Agree; 3 = Neutral; 2 = Disagree; 1 = Strongly Agree. The 43 items were sent to the five experts to review for content validation. The experts agreed to eliminate 13 items. Thus, there were 30 items remaining.

\section{Exploratory Factor Analysis (EFA)}

The aim of the exploratory factor analysis was to examine the loading patterns of QWL items. A principal component and orthogonal rotation (Verimax method) were chosen. It showed there were five structural factor patterns. In addition, any items demonstrated a factor loading value lesser than 0.40 were excluded (Deng, 2010). In this stage, cross loadings were taken into account as the higher loading value would be chosen to remain into the pattern. As a result, in this effort, there were 27 items retaining. However, the Kaiser-Meyer-Olkin (KMO) measure must be considered if its value is greater than 0.5 , which means the sample size is adequate. The KMO demonstrated at 0.93 , which is a satisfactory value that means EFA can be performed. In Table 1, it illustrates the factor loadings of the total 30 items.

Table 1

Rotated Component Matrix for the 30 Items

\begin{tabular}{lccccccccc}
\hline & Dimension 1 & \multicolumn{3}{c}{ Dimension 2 } & & Dimension 3 & \multicolumn{3}{c}{ Dimension 4 } \\
\hline I.7 & 0.80 & I.14 & 0.58 & I.1 & 0.57 & I.18 & 0.21 & Dimension 5 \\
I.8 & 0.71 & I.20 & 0.49 & I.2 & 0.69 & I.25 & 0.63 & I.6 & 0.42 \\
I.13 & 0.67 & I.21 & 0.51 & I.4 & 0.82 & I.26 & 0.58 & I.10 & 0.47 \\
\hline
\end{tabular}




\begin{tabular}{lllllllllll}
\hline I.15 & 0.65 & I.22 & 0.57 & I.5 & 0.67 & I.27 & 0.44 & I.11 & 0.66 \\
I.16 & 0.44 & I.23 & 0.71 & I.9 & 0.499 & I.28 & 0.643 & I.12 & 0.467 \\
I.19 & 0.40 & I.24 & 0.67 & I.17 & 0.3 & I.29 & 0.77 & I.30 & 0.20 & . \\
\hline
\end{tabular}

The eigenvalue was also considered as it represents the amount of information captured by a factor, and any factor with an eigenvalue less than 1.0 should be removed from the scale (Kaiser, 1991). Table 2 presents the cumulative percentage of the five dimensions of QWL. Overall, the total explanation of variance of the five dimensions was $60.133 \%$.

Dimension 1 included six items, illustrating eigenvalue $=9.307$, which explained $60.133 \%$ of the variance. Most of the items in this dimension related to Human Resource Management and Development, e.g., "My airlines have a good compensation system" (Item 7). Thus, this dimension was labelled as "Human Resource Management".

Dimension 2 included six items, indicating eigenvalue $=2.747$, which added $9.156 \%$ to the total variance explanation. The six items including in this dimension referred to relationship in the workplace, e.g., "I have a friendly and collaborative working environment" (Item 23). Therefore, this dimension was named as "Social Relation".

Dimension 3 was the five items, indicating eigenvalue $=2.332$, which added $7.772 \%$ to the total variance explanation. The five items were involved with safety at the workplace, e.g., "My company has a good standard of quality assurance system to ensure safety at the workplace" (Item 29). Thus, this dimension was labelled as "Safe Working Environment".

Dimension 4 was the five items, illustrating eigenvalue $=2.021$, which added $6.738 \%$ to the total variance explanation. The five items related to ways of living and how to manage pilots' personal and professional time, e.g., "I am able to manage my time to do some exercise" (Item 29). Thus, this dimension was named as "Work-Life Balance".

Finally, Dimension 5 included five items, indicating eigenvalue $=1.633$, which added $5.445 \%$ to the total variance explanation. The items were related to fair treatment within the organization and receive respect from other people, e.g., "My organization shares information that relate to my profession transparently" (Item 23). Thus, this dimension was called as "Fairness and Respect".

Table 2

Total Variance Explained of Five Dimensions of Pilots' QWL

\begin{tabular}{llll}
\hline Dimension & Eigenvalues & & \\
\cline { 2 - 4 } & Total & Variance (\%) & Cumulative (\%) \\
\hline Human Resource Management and Development & 9.30 & 31.02 & 31.02 \\
Social Relation & 2.75 & 9.16 & 40.17 \\
Safe Working Environment & 2.33 & 7.78 & 47.95 \\
Work-Life Balance & 2.02 & 6.74 & 54.69 \\
Fairness and Respect & 1.63 & 5.45 & 60.13 \\
\hline
\end{tabular}

\section{Discussion, Recommendations, and Conclusion}

Work environment of pilot involves all the physical aspects of work that determines the performance of pilots (Maurino, Reason, Johnston, \& Lee, 2017). Such working environments include safe high-technology and a program in which requires a lot of knowledge and training from the pilots. Apart from the mentioned factors, family lives, colleagues at work, and the opportunity for career growth also influence the overall performance of pilots. Results 
from the study shows that QWL of pilots consists of five dimensions. First, Safe Working Environment - this dimension pays attention on the airworthiness of equipment, cockpit and cabin crew, and the relevance of the maintenance physical workplace and workers. This also involves the safety awareness of individuals who are on the duty. Second, Human Resource Management and Development-this dimension refers to the sense of pilots' feeling secured in their own job especially their financial situation which motivates them to keep their job with the company they are working for. This also includes opportunities to grow in terms of career development within their company. It can be said that such HRM and HRD policies are the reflection of the visions, policy, professional learning and development, and adequate compensation and benefits of the company. Third, Fairness and Respect-this dimension discusses about the perception of fairness among pilots whether they receive fair treatment from their company as well as receive respect from different stakeholders. Fourth Dimension is Social Relation, which refers to the perception of having a healthy social relationship between them and team, supervisors, and other organisational members. It also includes their perception of having trust and support-from people they are working with. Last, Work-Life Balance dimension, this is about the ability of pilots to manage the amount of limited time they have on work and other aspects of their lives such as family, personal interest, mental and physical health. This can also be supported through organisational health promotion activities initiated by their company.

Further, for the future research, it may be interesting to examine the relationship between the level of perception of QWL among pilots and other variables such as happiness, organisational commitment, and accident and incident rates. Further, the model of Pilots' QWL may be used as a foundation for future research to statistically test it. The model may be suitable for different work functions in the aviation industry.

\section{References}

Adhikari, D. R., \& Gautam, D. K. (2010). Labour legislations for improving quality of work life in Nepal. International Journal of Law and Management, 52(1), 40-53.

Burchell, M., \& Robin, J. (2011). The great workplace. How to build it, how to keep it, and why it matters. San Francisco: Jossey-Bass.

Chatthai, T. (2016). Quality of working life of personnel at Dhurakij Pundit University. A research report.

Civil Aviation Safety Authority. (2017). Pilot wellbeing. Retrieved from https://www.casa.gov.au/wellbeing

Cunningham, J. B., \& Eberle, T. (1990). A guide to job enrichment and redesign. Personnel, 67, 56-61.

Daubermann, D., \& Pamplona, T. V. (2012). Quality of work life of nurses in primary health care. Acta Paulista de Enfermagem, 25(2), 277-283.

Deng, L. (2010). The City worker Mental Health Scale: A Validation Study. In L.T. Lam (Ed.), Psychological and Health-Related Assessment Tools Developed in China (pp. 34-44). Sharjah, UAE: Bentham Science Publishers.

Dorneich, M. C., Passinger, B., Hamblin, C., Keinrath, C., Vašek, J., Whitlow, S. D., \& Beekhuyzen, M. (2011). The crew workload manager: An open-loop adaptive system design for next generation flight decks. In Proceedings of the Human Factors and Ergonomics Society Annual Meeting (Vol. 55, No. 1, pp. 16-20). Sage CA: Los Angeles, CA: SAGE.

Federal Aviation Administration. (2013). Safety risk management. Retrieved from https://www.faa.gov/regulations_policies/handbooks_manuals/aviation/risk_management/

Gentili, R. J., Rietschel, J. C., Jaquess, K. J., Lo, L. C., Prevost, C. M., Miller, M. W., ... \& Hatfield, B. D. (2014). Brain biomarkers based assessment of cognitive workload in pilots under various task demands. In Engineering in Medicine and Biology Society (EMBC), 2014, 36th Annual International Conference of the IEEE (pp. 5860-5863). IEEE.

Gibb, R., Ercoline, B., \& Scharff, L. (2011). Spatial disorientation: Decades of pilot fatalities. Aviation, Space, and Environmental Medicine, 82(7), 717-724.

Hayrol, M. S., Jegak, U., Asiah, M., Noor, A. A., Bahaman, A. S., Jamilah, O., \& Thomas, K. (2010). Can quality of work life affect work performance among government agriculture extension officers? A case from Malaysia. Journal of Social Science, 6(1), 64-73.

Heidari, R. A., Enayati, N. A., \& Hedayati, A. (2010). Quality of work life and job satisfaction among the nurses of Tehran 
University of Medical Sciences. Dena Journal, $5(3$ \& 4), 28-37.

Hunker, I. K. (2014). Quality of work life in the hospitality industry-The contingent workers' perspective. Copenhagen Business School.

Ilkhanizadeh, S., \& Karatepe, O. M. (2017). An examination of the consequences of corporate social responsibility in the airline industry: Work engagement, career satisfaction, and voice behavior. Journal of Air Transport Management, 59, 8-17.

Jayakumar, A., \& Kalaiselvi, K. (2012). Quality of work life-an overview. International Journal of Marketing, Financial Services \& Management Research, 1(10), 140-151.

Kaiser, H. F. (1991). Coefficient alpha for a principal component and the Kaiser-Guttman rule. Psychological reports, 68(3), 855-858.

Krueger, P., Brazil, K., Lohfeld, L., Edward, H. G., Lewis, D., \& Tjam, E. (2002). Organization specific predictors of job satisfaction: Findings from a Canadian multi-site quality of work life cross-sectional survey. Retrieved from http://www.biomedcentral.com/content/pdf/1472-6963-2-6.pdf

Lau, R. S. M. (2000). QWL and performance: An ad hoc investigation of two key elements in the service profit chain model. International Journal of Service Industry Management, 11(5), 422-437.

Maurino, D. E., Reason, J., Johnston, N., \& Lee, R. B. (2017). Beyond aviation human factors: Safety in high technology systems. NY: Routledge.

Mirsepasi, N. (2005). Strategic human resource management and working relations (envisioning globalization). Tehran: Mir Publication.

Nekouei, M. H., Othman, M. Bt., Masud, J. Bt., \& Ahmad, A. Bt. (2014). Quality of work life and job satisfaction among employee in government organizations in IRAN. Journal of Basic and Applied Scientific Research, 4(1), 217-229.

Otto, J. L., \& Webber, B. J. (2013). Mental health diagnoses and counseling among pilots of remotely piloted aircraft in the United States Air Force. Medical Surveillance Monthly Report, 20(3), 3-8.

Robbins, S. P. (1989). Organizational behavior: Concepts, controversies, and applications. New Jersey: Prentice Hall.

Rossi, A. M., Perrewee, P. L., \& Sauter, S. L. (2006). Stress and quality of working life. Greenwich: Information Age Publishing.

Srivastava, S., \& Kanpur, R. (2014). A study on quality of work life: Key elements \& it's implications. IOSR-JBM, 16(3), 54-59.

Thompson, M. N., \& Subich, L. M. (2006). The relation of social status to the career decision-making process. Journal of Vocational Behavior, 69(2), 289-301.

Von dem Knesebeck, O., Mnich, E., Angermeyer, M. C., Kofahl, C., \& Makowski, A. (2015). Changes in depression stigma after the Germanwings crash-findings from German population surveys. Journal of Affective Disorders, 186, 261-265.

Walton, R. E. (1975). Criteria for quality of working life. In L. E. Davis, A. B. Cherns, and associates (Eds.), The quality of working (pp. 91-104). New York: The Free Press.

Wiegmann, D. A., \& Shappell, S. A. (2017). A human error approach to aviation accident analysis: The human factors analysis and classification system. NY: Routledge. 